\title{
DO ESTADO À MICROPOLÍTICA: LAÇO SOCIAL E MODALIDADES
} DE (R)EXISTENNCIA

\author{
DEL ESTADO HASTA LA MICROPOLITICA: LAZO SOCIAL Y MODOS DE \\ (R) EXISTENCIA \\ FROM STATE TO MICROPOLITICS: SOCIAL BOND AND MODALITIES \\ OF (R)EXISTENCE
}

http://dx.doi.org/10.1590/1807-03102015v28n1p026

Pedro Henrique Lucas Costa, João Luiz Leitão Paravidini, Caio César Souza Camargo Próchno e Anamaria Silva Neves

Universidade Federal de Uberlândia, Uberlândia/MG, Brasil

\section{RESUMO}

O presente artigo tem por objetivo discutir acerca do Laço Social, partindo de sua formalização institucional pelo Estado e articulando - em relativa contraposição - com a noção de micropolítica, enquanto possibilidade alternativa de existência social e resistência em relação ao desamparo e ao status quo. À luz da psicanálise, em especial às obras sociais de Sigmund Freud e às leituras de Eugène Enriquez a respeito das formações sociais, procuramos compreender a relação entre a gênese da sociabilidade na horda primeva e o atual Estado moderno, levando em consideração as implicações de sua instrumentalização para perpetrar modos de opressão, exclusão e violência. Pela ótica da Esquizoanálise, abordamos a questão da micropolítica como propiciadora de linhas de fuga - em relação ao domínio estatal mantenedor da ordem imposta, absorvida e reproduzida - para fomentar novas e produtivas formas de estabelecer laços sociais.

Palavras-chave: laço social; micropolítica; estado; resistência.

\section{RESUMEN}

Este artículo tiene como objetivo discutir sobre el lazo social, a partir de su formalización institucional por parte del Estado y en articulación - en parcial contraste - con la noción de micropolitica, como una posibilidad alternativa de la existencia social y la resistencia contra lo desamparo y el status quo. A la luz del psicoanálisis, especialmente las obras sociales de Sigmund Freud y lecturas de Eugène Enriquez sobre las formaciones sociales, tratando de entender la relación entre la génesis de la sociabilidad en el horda primitiva y el Estado moderno actual, teniendo en cuenta las implicaciones de su instrumentalización para perpetrar los modos de opresión, la exclusión y la violencia. Desde la perspectiva de esquizoanálisis, abordamos el tema de la micropolítica como prenda de líneas de fuga - en relación con el dominio mantenedor del estado de orden impuesto, absorto y reproducido - promover nuevas y productivas formas de establecer lazos sociales.

Palabras clave: lazo social, micropolítica, estado, resistência.

\begin{abstract}
This article aims to discuss the Social Bond, from its institutional formalization by the State and articulating - in relative contrast - with the notion of micropolitics, as an alternative possibility for social existence and resistance to the helplessness and the status quo. In light of psychoanalysis, particularly the social works of Sigmund Freud and readings from Eugène Enriquez about the social formations, we tried to understand the relationship between the genesis of sociality in the primal horde and the current modern State, taking into account the implications of its instrumentation to perpetrate modes of oppression, exclusion and violence. From the standpoint of Schizoanalysis, we address the issue of micropolitics as a pledge of lines of flight - in relation to the State domain, maintainer of the imposed, absorbed and reproduced order - to foster new and productive ways to establish social bonds.
\end{abstract}

Keywords: social bond; micropolitics; state; resistence. 


\section{Introdução}

Meados de junho de 2013. Um aumento na tarifa do transporte coletivo da maior cidade do Brasil, alguns revoltosos se articulam por meio das redes sociais para protestar, uma reação truculenta da polícia: os ingredientes básicos para um imenso e imprevisível levante popular, lançando mais de um milhão de pessoas às ruas do país, estão colocados no caldeirão borbulhante. Outros ingredientes, guardados há muito tempo, esperavam o momento oportuno para também serem utilizados no tempero - corrupção, questionável qualidade dos serviços de saúde e educação, avalanche tributária e etc - e a insatisfação generalizada se manifestava por meio dos mais diversos sabores. Por mais variadas que fossem as iguarias e os condimentos, algo os mantinha interconectados, os fazia compor um mesmo caldo, heterogêneo, mas ainda assim coeso. Além disso, o modo autogestivo e rasteiro com que tais ingredientes se ligavam era singular.

Eis uma ilustração que fomenta o questionamento a respeito da natureza do meio de mistura do socius, o líquido no qual se cozinha as composições sociais, tomando como um relevante objeto de estudo as minúsculas e não pré-formatadas - mas coextensivas - modalidades de enfrentamento. Desse modo, o objetivo deste artigo é promover uma discussão sobre os elementos catalizadores, de ordem intersubjetiva, que permitem o engendramento de agenciamentos coletivos enquanto modalidades de resistência à determinada normalidade e normatividade que preconiza a manutenção de certo estado de coisas.

$\mathrm{O}$ estabelecimento de interlocuções com os conceitos de Estado, Laço Social e Micropolítica possibilitará um trânsito entre saberes distintos - Sociologia, Psicanálise e Esquizoanálise borboleteando sorrateiramente pelos vários autores, buscando auxílio na complexa e inevitavelmente provisória compreensão do fenômeno em questão. Tentar articular conceitos de perspectivas teóricas diferentes - e até certo ponto divergentes - pode exigir um grande esforço e pouca garantia de sucesso. No entanto, tal exercício pode ser por si só produtor de saber, pois é na passagem, no passeio, mesmo que ardiloso, que é possível a construção e a desconstrução de sentidos para um conceito, sendo, então, um promissor ato filosófico.

A exemplo de Deleuze e Guattari, para os quais filosofia é a arte de criar conceitos, passeando por eles - conceitos enquanto passagem de sentidos "roubaremos" e seremos bricoleurs, transformandoos. Ou, conforme Baremblitt (2010) apresenta a postura de Deleuze em Diálogos, onde afirma que o seu método de criação teórica é um aproximar-se sigilosamente de um autor, pelas costas, e fazer-lhe um filho monstruoso, em que ele não se reconheceria. Não no sentido pejorativo do não reconhecimento, mas no seu sentido surpreendente em relação à forma impensável e maravilhosa criada a partir de um conceito.

\section{Laço social - militância frente ao desamparo}

Militante, segundo o dicionário Houaiss (2009), é aquele que milita, que combate, que defende ativamente uma causa. A partir desta perspectiva, podemos discutir sobre o papel do laço social como estratégia de defesa perante o desamparo. Chamaremos de militância para enfatizar o cunho político de tal estratégia, uma política do desejo.

Ceccarelli (2009), remetendo a Freud, relembra que o desamparo - na acepção que aqui nos interessa - não concerne apenas ao período de completa dependência do recém-nascido, mas também ao desamparo de ordem psíquica, advindo da impossibilidade do bebê de lidar com as exigências pulsionais filogeneticamente herdadas. Dessa forma, Eros produz investimentos libidinais de ordem imaginária e alucinatória para confortar o Eu em formação. A intensa dependência fisiológica se converte paulatinamente em dependência psíquica e posteriormente, como nos revela Ceccarelli (2009), tal dependência será o mote inicial das diversas formações socioculturais e discursivas, indicando as possibilidades para se lidar com o desamparo.

A dependência primordial é forjada em relação aos pais e depois se passa a crer que os deuses ou outras entidades sobrenaturais farão o papel de proteção inabalável e ilimitada. Essa estratégia de defesa quanto ao desamparo é ilusória, no sentido de nos proporcionar a sensação de conforto, proteção e acolhimento oferecida pelo outro, perante a completa desolação.

Importante ressaltar que a ilusão no sentido freudiano - ideia bem desenvolvida em $O$ Futuro de uma Ilusão - remete não a um engano de percepção ou cognição, mas se articula com o desejo. De acordo com Freud (1927/1996), “o que é característico das ilusões é o fato de derivarem de desejos humanos" (p. 20). Sendo assim, essa ilusão é a síntese de uma crença motivada pela realização do desejo. Ceccarelli (2009) exibe a tese de que tal ilusão geradora de produtos culturais e ligações simbólicas coletivas é análoga àquilo que Lacan chamou de Laço Social. 
Trocando por miúdos, o estrato simbólico que estará à disposição do sujeito na medida em que se desenvolve lhe dará condições mínimas para melhor lidar com a condição de desamparo psíquico. Tal sustentação simbólica, além de ser invariavelmente calcada em um sistema social de crenças (pela definição freudiana: crenças animistas, religiosas e/ou científicas) ao qual o sujeito está aderido, não é capaz de oferecer uma solução perfeita e completa frente ao desamparo e às exigências pulsionais.

Lacan (1969-1970/1992) cunhou o conceito de laço para determinar as quatro fórmulas do discurso e a maneira pela qual tais discursos fomentam laços sociais como modo de adesão do sujeito ao simbólico, ou seja, ao Outro e sua dimensão de poder. A relação de dominação e a adesão do sujeito à ordem do discurso se sustentam a partir da inserção e dependência do mesmo ao registro simbólico. Em outras palavras, o discurso é linguageiro na medida em que o lugar ocupado na relação que se estabelece com a suposta Verdade, marcada pelo uso que se faz da linguagem (e seus desdobramentos em significantes), será determinante para definir o papel na relação de dominação. Por meio das configurações significantes Lacan elaborou os discursos do mestre, universitário, da histérica e do analista.

Para melhor compreensão da noção de laço social para Lacan e a sua articulação com os discursos, é pertinente recorrer a Miller (2005) em seu artigo "Psicoanálisis y sociedad", no qual procura problematizar o lugar e a postura da psicanálise, a partir dos construtos lacanianos, em relação à sociedade. Um dos questionamentos fundamentais interpostos por Miller diz respeito ao próprio conceito de sociedade, sendo, por si só, um conceito duvidoso que requer um ato de fé para ganhar materialidade e produzir efeitos, tal qual uma divindade. $\mathrm{O}$ conceito de sociedade tem um caráter totalizante, total e completo (como um círculo que se fecha perfeitamente e de modo absolutamente harmonioso), por isso, Lacan, demarcando uma diferença conceitual, elabora a noção de laço social a fim de evidenciar que, mesmo de forma instável, variável, incompleta e plural, o sujeito - e suas instâncias psíquicas - não se consolidam em meio a um solipsismo, estando sempre no campo do Outro (campo esse que inclusive precede o próprio sujeito, sendo fundamental para a sua constituição). Miller destaca que, conforme Lacan, o laço social é uma relação de dominação, importando, então, saber o lugar que se ocupa nessa relação (o de dominado ou o de dominador). O laço social não consiste em uma relação pacífica em que haja um todo harmônico composto pelos sujeitos - é por origem, segundo o entendimento de Miller, um laço assimétrico (por esse motivo, a dialética do senhor e do escravo de Hegel é uma das fontes de inspiração para Lacan na elaboração dos quatro discursos, em especial o discurso do mestre).

Ao longo da história da humanidade, o laço social se estabeleceu de variadas maneiras, sendo então o sustentáculo fundamental da própria civilização. Freud (1927) considera a civilização o maior instrumento de dominação do homem perante as forças da natureza, no qual estão incluídos o conhecimento das técnicas e tecnologias de sobrevivência e as regras centrais para a convivência, calcadas em uma relevante renúncia pulsional. Em Mal-Estar na civilização, Freud (1930) evidencia o antagonismo entre as exigências da civilização e as da pulsão (é demandada uma paulatina redução dos ímpetos agressivos e sexuais em nome de uma convivência social minimamente sustentável). Inaugura-se com a civilização uma guerra desta contra o indivíduo. Em tese, far-se-ia necessário tal renúncia pulsional em nome de um maior grau de segurança para todos aqueles envolvidos no processo civilizatório. A satisfação pulsional é sempre parcial e eventualmente ocorrerá por meio do trabalho, fantasias, sublimação e outros mecanismos que o sujeito seja capaz de recorrer.

Por meio da civilização e das produções culturais dela oriundas, o laço social se materializou em diversas modalidades de organizações institucionais, enquanto formações que sedimentam os modos prevalentes de lidar com o desamparo e seus desdobramentos.

Na primeira parte de sua obra Da horda ao Estado, Eugène Enriquez (1990), baseado nas obras sociais de Freud, apresenta-nos, de modo bastante pertinente, o desenvolvimento da cultura e dos vínculos sociais intrínsecos a ela a partir de uma visão psicanalítica. Ele parte do mito freudiano da horda primeva e do assassínio do chefe patriarcal dito real que, graças a sua morte, ascende à ordem simbólica enquanto lei de identificação, contenção e proscrição (primordialmente no que tange ao incesto). Evidencia então que a civilização nasce por meio da repressão e, posteriormente, se valerá das instituições - sistemas de repressões coletivas - para se instrumentalizar. Mais adiante, ele passa a discutir a obra Psicologia das massas e análise do Eu (1921), reafirmando a indissociação dos constructos psíquicos individuais em relação aos sociais e a influência das massas em relação ao indivíduo por meio do discurso e da palavra, além de ressaltar o desaparecimento da sensação de impossibilidade ou limitação a partir da imersão do sujeito na massa. Em seguida é feita uma leitura de O Futuro de uma ilusão (1927), para revelar como os desejos narcísicos engendram ilusões coletivas - 
citando a Igreja - a fim de ocultar a realidade e justificar a imposição de determinadas condutas socialmente aceitáveis, funcionando como um "superego coletivo". O autor aborda também o já citado Mal-Estar na Civilização (1930), que, em contraposição à ideia inicial de apaziguamento e pacificação através da cultura, o mal-estar se instala graças à renúncia pulsional necessária. Aqui ele enfatiza o ódio como o mais fecundo elo entre os indivíduos que se amotinam em um grupo para se engajar na aniquilação de outro grupo, ao qual o ódio está endereçado - passando o amor a ser visto apenas como uma aliança motivada inicialmente pelo profundo ódio. Passa a ser pregnante, nessa perspectiva, a constatação de que a pulsão de morte é inerente à própria civilização. Em seguida, retomando Moisés e o Monoteísmo (1939), volta a abordar a religião, advogando que esta é um sistema fechado que oferece certezas apaziguadoras e não saberes que seriam frutos do confronto com a dúvida. Discute ainda como o antissemitismo é oriundo de um ódio a um povo que se considera escolhido por Deus, mesmo sem ter assumido o parricídio, como os cristãos (que, por sua vez, assumem a responsabilidade da morte do pai na figura de Cristo) e também se consideram os escolhidos. Em Reflexões atuais sobre a guerra e a morte (Freud, 1915/1996), escritos em que ele pergunta se a civilização caminha para a destruição absoluta, tendo em vista que ela nasceu a partir de um crime, além de destacar o papel do Estado enquanto instância formal maior de regulação das relações dos indivíduos e de monopólio da violência que então se autoriza a fazer guerra como forma de satisfazer a tendência à agressividade. Na primeira parte da obra, Enriquez fecha com o debate sobre o vínculo social aqui podendo ser tomado de modo estreito ao conceito de laço social - que seria a organização humana frente ao caos. Importante mencionar a noção de ordem hierárquica como embates de forças impostas aos indivíduos, que se digladiam para se diferenciar uns dos outros. Daí advêm as classificações sociais hierárquicas e formalmente instituídas, como raças, classes econômicas, gêneros, idades e etc. Em suma, na obra Da horda ao Estado, Enriquez não se preocupa em apresentar uma evolução histórica da horda ao Estado, mas estabelece uma relação paralela entre as duas composições sociais, de modo análogo.

Da horda ao Estado é um dos mais relevantes trabalhos de Enriquez, pois disserta acerca das artimanhas da formação da lógica estatal a partir do mito primevo. Reconhecendo essa possibilidade teórica, cabe trazer à discussão aquilo que não ingenuamente é conhecida como utopia freudiana (talvez também da ordem da ilusão), a ideia de que o homem, por meio da suposta evolução cultural (kulturarbeit, o trabalho da cultura), estaria em pleno progresso no que se refere ao enfrentamento de sua renúncia pulsional, do desamparo e da sociabilidade, indo da fase animista, passando pela religiosa, até adentrar a era científica, segundo sintetiza Ceccarelli (2009). Todavia, no advento da primeira guerra mundial, Freud se desilude ao perceber que todo o acúmulo cultural não garante a preservação da paz e da vida humana. Para Ceccareli, a desilusão freudiana é fruto da escancarada revelação da ineficácia dos expedientes utilizados para lidar com o desamparo (além de falhos, produzem guerras, mortes e variados tipos de sujeição e aniquilação do outro). A própria cultura - ou a civilização - cria dispositivos de recalque e repressão para disfarçar o mal-estar gerado pelo processo civilizatório.

Além de mascarar o mal-estar, pode perpetuar a violência, agora autorizada:

O Estado proíbe ao indivíduo a prática do mal, não porque deseja aboli-la, mas porque deseja monopolizá-la, tal como o sal e o fumo. Um Estado beligerante permite-se todos os malefícios, todos os atos de violência que desgraçariam o indivíduo ... O Estado exige o grau máximo de obediência e de sacrifício de seus cidadãos; ao mesmo tempo, porém, trata-os como crianças, mediante um excesso de sigilo e uma censura quanto a notícias e expressões de opinião, que deixa os espíritos daqueles, cujos intelectos ele assim suprime, sem defesa contra toda mudança desfavorável dos eventos e todo boato sinistro. Exime-se das garantias e tratados que o vinculavam a outros Estados, e confessa desavergonhadamente sua própria capacidade e sede de poder, que o cidadão tem então de sancionar em nome do patriotismo. (Freud, 1915/1996, p. 289)

Nessa perspectiva, as instituições, em especial as que representam o Estado, podem ser entendidas como uma encarnação ou cristalização do laço social, autorizadas pela legalidade e pela legitimidade que intenta oferecer certo nível de segurança, ordem e estabilidade para a sociedade, à custa de operar, por outro lado, diversas formas de opressão, exclusão e violência, determinando e fazendo cumprir o que é aceitável e o que não é. Neste ponto, poderíamos lançar mão da ideia, reconhecendo as importantes diferenças epistemológicas entre os autores, de que é por meio das instituições que os aparelhos de Estado, como denominou Althusser (1985), se fazem exercer. O exercício de poder do Estado, nessa perspectiva althusseriana, está totalmente ligado às determinações da classe dominante, cujo fator da reprodução da dominação na esfera estatal é indispensável para uma adequação do explorado à dominação também no âmbito produtivo. Cabe salientar que não se trata de uma forma explícita de dominação, mas sim permeada 
por mistificação ideológica que garante certa coesão da sociedade e uma adesão mais ou menos pacífica em relação aos ditames da ordem social vigente. Ainda de acordo com Althusser (1985), são os aparelhos ideológicos de Estado que possibilitam tal controle através do discurso, diferentemente dos aparelhos repressivos de Estado que se exercem através da violência. A força da ideologia se faz manifesta a partir de instituições sedimentadas com a finalidade de organizar e perpetrar a ideologia da classe dominante. Dentre as instituições com essa finalidade, temos os partidos, sindicatos, igreja, família, com especial destaque para a escola, como instituição que assumiu o papel principal para doutrinação ideológica.

Já em outra concepção que em certa medida contemporiza o entendimento do papel institucional, Kaës (1997) revela que a instituição ainda provê uma estabilidade ilusória que dá uma mínima sustentabilidade ao sujeito - o que ele chama de apoio psíquico - além de gerar atribuições sociais identitárias mediante um contrato narcísico. Tal contrato se torna possível graças a um deslocamento que o sujeito faz da figura do pai, em sua condição de provedor de cuidados, ao Estado.

Mas, por outro lado, o Estado poderia, em muitos casos, fazer às vezes do pai real incestuoso da ordem primeva, como afirma Enriquez (1990):

O Estado (herdeiro da onipotência do pai primevo), como bem salientou Kaufmann, toma tudo a si sem nada dar; o Estado é a instituição que permite à pulsão de morte se desenvolver completamente; finalmente, o Estado (enquanto supressor da sociedade primitiva, sociedade guerreira) não protege contra a guerra de todos contra todos, como acreditava Hobbes, mas exatamente o contrário, apesar da aparência indulgente que ele assume em tempos de paz. Ao se anunciar como o sustentáculo da sociedade pacífica, o Estado se institui como único corpo do desejo e da expressão da verdade. A consequência de tal afirmativa é bem conhecida: ser o único, colocando-se no lugar da verdade, só pode conduzir a humanidade a seu fim. Como já havíamos dito em outro trabalho: 'O crescimento do Estado, e sua cristalização, é a generalização da castração e da morte'. (Enriquez, 1990, p. 143)

Mais adiante, o mesmo autor reafirma tal constatação destacando o papel das instituições como instrumentos pelos quais o Estado se apropria e aplica a violência.

O Estado assume a violência do chefe da horda, assim como a dos irmãos conjurados. Ele a confiscou para seu próprio benefício. Entretanto, na maior parte do tempo, a violência tomará corpo sob a máscara das instituições, que servem à regulação social. Ela assumirá o nome de lei, de norma ou de regulamento. Sua sutileza e moderação não impedirão de marcar os espíritos, de penetrar nas consciências, de guiar as ações, na falta de castigos mais severos. (Enriquez, 1990, p. 359)

Recorrendo à psicanálise para apreender a relação com o Estado, Hur (2011) entende que tal área do conhecimento pode auxiliar na compreensão da maneira pela qual essa instituição (ou conglomerado de instituições) se consolida enquanto aparato de violência que acaba por atualizar o despotismo do pai real da horda, tendo como interesse preponderante a perpetuação de si mesmo em detrimento dos indivíduos sob sua tutela.

Pensando por esse viés, a questão que se interpõe é como conceber as formas alternativas que o laço social se constrói (indo para além daquilo que é considerado o poder constituído e institucionalizado) que se dissemina pelo microcosmo social e que acabam por promover abalos na ordem do dia. Para isso, é fecundo pensar na noção de micropolítica, principalmente a partir da concepção dos esquizoanalistas, em especial, Deleuze e Guattari.

\section{Micropolítica - guerrilha e outros laços sociais}

Segundo Castoriadis (1982), há um senso comum de que o Estadoé uma instituição natural e indispensável para a regulação das diversas modalidades de relações sociais, sem que se reconheça que é uma modalidade de organização social historicamente situada e contextualmente engendrada.

Os homens procuram o Estado e as instituições incitados pela crença de que, por meio de tais dispositivos, poderiam enfrentar a absoluta condição de desamparo. O que pode se revelar nessa busca por amparo é exatamente outra forma de desamparo, não apenas marcada pela negligência, mas também pela opressão, violência e exclusão. A heteronomia da horda não é superada, mas ascende a outro nível quando içada ao patamar do poder estatal. Contudo, isso não cessa de produzir agenciamentos e encontros nas entrelinhas e nas brechas do próprio Estado ou naquilo para além (ou aquém) dele.

Para pensarmos a questão do poder e sua microfísica para além de sua modalidade estatal instituída e formalizada, cabe retomar a noção de Foucault para relembrarmos que o poder

não é algo que se possa dividir entre aqueles que o possuem e o detêm exclusivamente e aqueles que não o possuem e lhe são submetidos. $\mathrm{O}$ poder deve ser analisado como algo que circula, ou melhor, 
como algo que só funciona em cadeia. Nunca está localizado aqui ou ali, nunca está nas mãos de alguns, nunca é apropriado como uma riqueza ou um bem. $\mathrm{O}$ poder funciona e se exerce em rede. Nas suas malhas, os indivíduos não só circulam, mas estão sempre em posição de exercer este poder e de sofrer sua ação; nunca é o alvo inerte ou consentido do poder, são sempre centros de transmissão. Em outros termos, o poder não se aplica aos indivíduos, passa por eles. (Foucault, 2000, p. 183)

Conforme dito anteriormente, Enriquez (1990) sustenta a ideia de que o Estado fomenta determinadas ordens hierárquicas e classificatórias como forma de organização frente ao caos, instituindo, desse modo, uma segmentaridade. Em consonância com tal afirmação, é a partir da noção de segmentaridade que Deleuze e Guattari (2012) iniciam a discussão sobre micropolítica em Mil Platôs. Os autores afirmam que nas sociedades primitivas há também uma modalidade de segmentaridade que instaura linhas organizadoras, delimitando os espaços, os gêneros, as regras e etc. Por não haver nessas sociedades um aparelho estatal central fixo, nem poder global ou instituições políticas, os segmentos sociais dispõem de certa flexibilidade e plurivocidade. Não há necessariamente nenhuma oposição entre segmentaridade e centralidade, visto que nas sociedades com Estados também existem segmentos, mas, neste caso, segmentos impostos pelo poder central. A segmentaridade estatal é centralizada, enrijecida e formalizada pelas tecnocracias e burocracias. Apesar de tal diferenciação entre a segmentação primitiva e a moderna, as duas modalidades são inseparáveis, de maneira que na primeira há também determinados núcleos duros molares - que conjurariam o Estado e exerceriam uma sobrecodificação do todo, assim como na segunda há a presença de um tecido flexível, dotado de certa liquidez - molecular - do qual a própria centralização necessita para se propagar.

\section{Deleuze e Guattari afirmam:}

Em suma, tudo é político, mas toda política é ao mesmo tempo macropolítica e micropolítica. Consideremos conjuntos do tipo percepção ou sentimento: sua organização molar, sua segmentaridade dura, não impede todo um mundo de microperceptos inconscientes, de afectos inconscientes, de segmentações finas, que não captam ou não sentem as mesmas coisas, que se distribuem de outro modo, que operam de outro modo. Uma micropolítica da percepção, da afecção, da conversa, etc. (Deleuze \& Guattari, 2012, p. 99)

Dessa forma, evidencia-se que tais autores nos apresentam formas de pensar o Estado para além do familismo da psicanálise na qual existe a tendência de desdobrar todo o agenciamento social a partir da formatação familiar. A noção de Estado como Aparelho de Captura (1976/2010) se faz pertinente para avançarmos no aspecto da micropolítica. Deleuze e Guattari (1976/2010) defendem que a sociedade é formada por uma multiplicidade incontável de fluxos. O socius teria a função de conter esse emaranhado caótico de fluxos e mantê-los dentro de uma configuração previsível de significações.

Para ilustrar a relação entre molar e molecular - ou macro e micropolítica - cabe a distinção entre os termos "massa" e "classe social", em que a massa é despida de identidade a priori, sendo então uma noção molecular, enquanto a classe, ainda que inscrita na massa, se cristaliza como um dado identificatório predeterminante e predeterminado. Vale salientar que as "massas" sempre estão escapando das "classes", no sentido de que estas últimas nunca fazem total e absoluta continência discursiva para a potência singular da massa, que é definida pela multiplicidade. O inverso também é possível e temos no fascismo o mais destrutivo exemplo disso, pois por meio de agenciamentos moleculares e micropolíticos, as ideias e práticas fascistas se disseminam e é só através dessa micrologia rastejante que o seu Estado totalitário pode se fazer estabelecer de modo definitivo.

Mesmo que o agenciamento micropolítico opere no detalhe, no infinitesimal e no corriqueiro, ele não é necessariamente pequeno (restrito ou limitado), pelo contrário, ele é coextensivo. E, na mesma medida, quanto mais forte a organização molar, mais ela deve se tornar coextensiva e molecularizada para conseguir exercer seu domínio. Desse modo, o Estado domina não apenas por meio de suas monumentais instituições repressoras-punitivas, econômicas ou educacionais, mas também por meio da legitimidade discursiva confirmada pelos pequenos medos e inseguranças compartilhadas entre os habitantes de um território de sobrecodificação. Utilizando a metáfora mítica freudiana, se houve um movimento instituinte e molecular na trama do assassínio do pai primevo, há uma recodificação molar na progressiva conversão da fratria em Estado, mas ela só é possível com a gradual metabolização molecular das partes da carne ingeridas pelos irmãos no banquete totêmico.

Há, portanto, uma ênfase dada à micropolítica enquanto um inegável - mas muitas vezes ignorado - elemento definidor da realidade social, realidade esta permeada por constantes movimentos de descodificações e desterritorializações.

Relendo a microssociologia de Gabriel Tarde, que trata os fenômenos sociais como ondas ou fluxos para além do âmbito individual, mas que perpassam 
e se propagam através dos indivíduos - Deleuze e Guattari denominam de fluxos mutantes aquilo que tende a escapar dos códigos e da captura e os quanta seriam os signos e graus de desterritorialização no fluxo descodificado (arte/mercadoria). Os fluxos se colocam em conexão (encontro de fluxos desterritorializados, produzindo linhas de fuga) ou conjugação (quando os fluxos são represados e reterritorializados em uma nova sobrecodificação).

Assim, é possível pensar em micropolítica como um agenciamento micrológico que dispõe de uma potência intempestiva para a transformação da ordem social e subjetiva enquanto campos indissociáveis, mas também (e aqui vai o alerta de Deleuze e Guatarri) pode engendrar modos de microfascismos, dando a sustentabilidade germinal a um possível Estado totalitário fascista. Nesse momento, tomando como foco as possibilidades de resistência às variadas formas de dominação e opressão, além do processo de singularização, podemos abordar a noção de revoluções moleculares apresentada no livro Micropolítica: cartografias do desejo de Suely Rolnik em parceria com Félix Guattari (1996).

Considerando as revoluções moleculares, a autora postula que:

O que vai caracterizar um processo de singularização (que, durante certa época, eu chamei de "experiência de um grupo sujeito"), é que ele seja automodelador. Isto é, que ele capte os elementos da situação, que construa seus próprios tipos de referências práticas e teóricas, sem ficar nessa posição constante de dependência em relação ao poder global, a nível econômico, a nível do saber, a nível técnico, a nível das segregações, dos tipos de prestígio que são difundidos. A partir do momento em que os grupos adquirem essa liberdade de viver seus processos, eles passam a ter uma capacidade de ler sua própria situação e aquilo que se passa em torno deles. Essa capacidade é que vai lhes dar um mínimo de possibilidade de criação e permitir preservar exatamente esse caráter de autonomia tão importante. (Guattari \& Rolnik, 1996, p. 46)

Destarte, a revolução molecular é micropolítica e o seu ponto fulcral é a autogestão. A micropolítica seria uma forma de atuação do desejo no campo social. O laço social, nessa perspectiva micropolítica, pode ser reinventado por vias subterrâneas, não mais comprometido com a sua formalização em forma de Estado ou ideologia dominante, inclusive podendo se opor a ela, reinventando também formas potentes, singulares de lidar com a condição de desamparo, não só referente à natureza ou à própria morte, mas ao próprio aparelho estatal enquanto promotor de mortificação.
Neste ponto, não há prejuízo em ir ao encontro das ideias de Clastres (1974/2003), importante antropólogo que, a partir da análise das sociedades indígenas, pode sustentar a constante possibilidade de uma vida e organização social para além do Estado. Para o autor, a análise antropológica etnocêntrica e viciada em estadismos jamais obteve sucesso em compreender o que se passava na sociedade dos povos ameríndios, pois se baseavam na perspectiva da tradicional política de poder e coerção. O que se evidencia é que, perante a ameaça das forças da natureza, o Estado não é uma solução universal apriorística unânime tampouco desprovida de historicidade.

A partir disso, o laço social pode fomentar linhas de fuga e novas maneiras de existir e resistir. Essa resistência não se dá em formato de guerra estatal, por meio de seus exércitos militares e centros de poder, mas por meio de táticas de guerrilha, descentralizadas, nômades e flexíveis.

\section{Últimas considerações}

Apesar das possíveis divergências teóricas que sustentam a noção de laço social em relação à micropolítica, promover a interlocução conceitual e conectá-las como 'fluxos de saber' é uma opção possível, pois se produz uma nova ordem de sentido, que consequentemente oferece novas formas de pensar os agenciamentos sociais na contemporaneidade. Um dos principais obstáculos para a articulação e o delineamento teórico presente neste trabalho - e que não pode ser relegado como inexistente - diz respeito à dificuldade de se colocar lado a lado a noção de desamparo, oriunda da Psicanálise, ao pensamento esquizoanalítico de Deleuze e Guattari. A dificuldade, com a qual se deve manter constante cautela, ocorre pelo fato de que a Esquizoanálise efetua um radical ataque às "categorias do negativo" presentes no arcabouço conceitual da Psicanálise, a saber, a ideia de castração, a pulsão de morte e o desejo calcado na falta, que em certo sentido podem estar articuladas com a ideia de desamparo. Deleuze e Guattari, especialmente em o Anti-édipo e Mil Platôs, defendem um afazer político-filosófico e uma vida completamente afirmativa, na qual o Desejo é concebido como produção incessante e não fruto de uma suposta falta fundamental. Reconhecidas essas diferenças e divergências epistemológicas, intentamos aqui, através do contato entre dois ou mais campos teóricos distintos, incutir uma possibilidade totalmente afirmativa e produtiva às noções e condições que explicitam a suposta incompletude humana. Retirouse do laço que nos liga ao outro o aspecto de uma mera 
e cinzenta condição necessária para a sobrevivência, passando, por conseguinte, a atribuir às relações sociais o caráter de uma possibilidade sempre inventiva.

Longe de desejar produzir conclusões definitivas sobre a temática, o intuito deste artigo é abrir a discussão sobre os fenômenos sociais que tem ocorrido atualmente no Brasil e no mundo, procurando estabelecer um olhar alternativo aos fatos que vêm sendo repercutidos amplamente. Movimentos populares, manifestações, levantes e revoltas têm chamado a atenção do mundo nos últimos anos, graças a sua velocidade, intensidade e impressionante diversidade (até mesmo com marcantes divergências entre eles, tanto de temáticas quanto de objetivo). Desde a Primavera Árabe iniciada em 2010, passando pelas manifestações na Grécia, graças à enorme crise econômica, e pelo movimento Occupy Wall Street em 2011, até os grandes protestos de junho de 2013 no Brasil e a revolta na Ucrânia, já no final do mesmo ano. Movimentos de demarcadas diferenças quanto às metas e reivindicações, mas todos trazem como elemento de propagação formas rasteiras e subterrâneas de se organizar, seja através das redes sociais na internet, seja por outros meios que não dependam da chancela, tutoria e administração direta dos mecanismos estatais de atuação no campo social. Não cabe aqui julgar a pertinência, a legitimidade ou até a moralidade de tais movimentos e inclusive de outros fenômenos sociais muito mais controversos e polêmicos como a agressiva tática Black Bloc ou os justiceiros do Rio de Janeiro que resolveram fazer o que eles consideraram justiça sem a supervisão do Estado. O que se intenta é detectar nesses acontecimentos os pontos sintomáticos que revelam formas de se fazer articulações políticas à revelia do Estado e aquilo que é por ele determinado como sendo democracia. Em outras palavras, a questão que se interpõe é: como isto funciona? (e não o que significa ou onde se originou).

Uma característica que parece ser própria de tais movimentos é o caráter efêmero e metamórfico, algo que é peculiar à micropolítica, pois os agenciamentos que se iniciam em altíssima intensidade logo tendem ou a se transformar em algo totalmente diferente daquilo que foi seu embrião ou a ser absorvido e ressignificado pela institucionalidade do Estado. Além disso, não podemos pensar o Estado e os agenciamentos micropolíticos ignorando a axiomática do capitalismo - com as suas leis de mercado de bens, serviços e trabalho, publicidade, e lógica monetáriofinanceira - e os processos de subjetivação capitalística oriundos da adoção generalizada dessa axiomática. Há uma profunda e estreita interface do Estado com suas políticas, com as leis e instituição de regulação das regras do capitalismo, por outro lado, há também uma micropolítica molecular na maneira que a lógica do capital financeiro neoliberal se propaga e se faz perene por todo o globo - denominado capitalismo rizomático, conforme aponta Araújo (2006) ou o Império segundo Hardt e Negri (2005). Dessa forma, a (r)existência micr opolítica também pode se direcionar ao plano do modo de produção e consumo, tendo em vista que não há dissociação entre aquilo que o Estado determina e aquilo que o capitalismo demanda. Interessa lembrar que Lacan (1969-1970/1992) chega a falar de um quinto discurso, precisamente o discurso do capitalista, que, de acordo com ele, é o único dos cinco que não estabelece laço social. Sendo assim, para propiciar inventivos laços sociais, micropolíticos e com a potência de resistir e produzir linhas de fuga, a guerrilha, eventualmente, também estabelecerá embates contra a hegemonia do capital. Falar em (r)existência denota assumir que há uma possível existência, que interpenetra os campos sociais e individuais, resistente à dominação e significa também reconhecer que há uma resistência existencial, enquanto constante afazer combativo via invenção da própria vida.

\section{Referências}

Althusser, L. (1985). Aparelhos ideológicos de Estado (V. J. Evangelista \& M. L. Viveiros Castro, Trads., $2^{\mathrm{a}}$ ed.). Rio de Janeiro: Graal.

Araújo, M. (2006). Sociedade de controle e capitalismo rizomático. Revista Critério, 6. Acesso em 17 de julho, 2013, em http://www.pucsp.br/nucleodesubjetividade/Textos/ capitalismo mguilherme.pdf

Baremblitt, G. (2010). Introdução à esquizoanálise. Belo Horizonte: Instituto Félix Guattari.

Castoriadis, C. (1982). A instituição imaginária da Sociedade. Rio de Janeiro: Paz e Terra.

Ceccarelli, P. R. (2009). Laço social: uma ilusão frente ao desamparo. Reverso, 31(58). Acesso em 17 de julho, 2013, em http://pepsic.bvsalud.org/scielo.php?script=sci arttext\&pid $=$ S0102-73952009000200004\&lng $=$ pt\&nrm $=\overline{\text { is }}$ o\&tlng $=\mathrm{pt}$

Clastres, P. (2003). A sociedade contra o Estado: pesquisas de antropologia política. São Paulo: Cosac Naify. (Original publicado em 1974)

Deleuze, G. \& Guattari, F. (2010). O anti-Édipo: capitalismo e esquizofrenia. São Paulo: 34. (Original publicado em 1976)

Deleuze, G. \& Guattari, F. (2012). Mil platôs: capitalismo e esquizofrenia (Vol. 3, 2a ed.). São Paulo: 34

Enriquez, E. (1990). Da horda ao Estado: psicanálise do vínculo social. Rio de Janeiro: Zahar.

Foucault, M. (2000). Microfisica do Poder (15 ed.). Rio de Janeiro: Graal.

Freud, S. (1915/1996). Reflexões para os tempos de guerra e morte. In Edição Standard brasileira das obras psicológicas completas de Sigmund Freud (Vol. XIV, pp. 281 - 309). Rio de Janeiro: Imago. (Original publicado em 1915)

Freud, S. (1927/1996). O futuro de uma ilusão. In Edição Standard brasileira das obras psicológicas completas 
de Sigmund Freud (Vol. XXI, pp. 15-66). Rio de Janeiro: Imago. (Original publicado em 1927)

Freud, S. (1930/1996). O mal-estar na civilização. In Edição standard brasileira das obras psicológicas completas de Sigmund Freud (Vol. XXI, pp. 67-150). Rio de Janeiro: Imago. (Original publicado em 1930)

Guattari, F. \& Rolnik, S. (1996). Micropolitica: cartografias do desejo ( $4^{\mathrm{a}}$ ed.). Petrópolis, RJ: Vozes.

Hardt, M. \& Negri, A. (2005). Império ( $7^{\mathrm{a}}$ ed.). Rio de Janeiro: Record.

Houaiss, A. (2009). Dicionário eletrônico Houaiss da língua portuguesa. Rio de Janeiro: Objetiva.

Hur, D. U. (2011). Psicanálise e política: considerações sobre o Estado. Revista Gestão \& Políticas Públicas, 1(1), 112-132. Acesso em 25 de fevereiro, 2014, em http://each.uspnet.usp. br/rgpp/index.php/rgpp/article/view/6

Kaës, R. (1997). O grupo e o sujeito do grupo: elementos para uma teoria psicanalítica do grupo. São Paulo: Casa do Psicólogo.

Lacan, J. (1969-1970/1992). O Seminário, Livro 17: o avesso da psicanálise. Rio de Janeiro: Zahar.

Miller, J-A. (2005). Psicoanálisis y sociedade. Freudiana, 4344, 7-30. Acesso em 12 de outubro, 2015, em http://www. eol.org. ar/template.. asp ? $\mathrm{Sec}=$ publicaciones $\&$ SubSec $=$ on $\underline{\text { line } \& \text { File }=\text { on line } / \text { psicoanalisis_sociedad } / \text { miller-ja }}$ lautilidad.html.

Submissão em 29/04/2014

Revisão em 01/10/2015

Aceite em 26/10/2015

\section{Agradecimento}

À agência de fomento, CAPES: bolsa de Demanda Social (de abril/2013 a fevereiro/2014).
Pedro Henrique Lucas Costa é mestrando em Psicologia Aplicada pela Universidade Federal de Uberlândia, no eixo temático da Psicologia da Intersubjetividade, na linha de pesquisa Psicopatologia, Psicanálise e Cultura. Psicólogo do Centro de Referência em Assistência Social em Uberaba. Endereço: Universidade Federal de Uberlândia, Instituto de Psicologia. Programa de Pós-graduação em Psicologia. Av. Maranhão, s/nº, Bloco 2C, Sala 2C54. Campus Umuarama. Bairro: Jardim Umuarama. Caixa Postal: 593, Uberlândia, MG, Brasil. CEP 38405318.

E-mail: luc1f3r 999@,hotmail.com

João Luiz Leitão Paravidini é doutor em Ciências Médicas pela Universidade Estadual de Campinas, pós-doutor pela Faculdade de Medicina de São José do Rio Preto, pós-doutor pela Universidade Federal de Minas Gerais.

Atualmente é Professor Associado da Universidade Federal de Uberlândia e da Prefeitura Municipal de Uberlândia. E-mail: jlparavidini@gmail.com

Caio César Souza Camargo Próchno é doutor em Psicologia Social pelo Instituto de Psicologia da Universidade de São Paulo, com pós-doutorado na Universidade de Leipzig, Alemanha. E-mail: c.prochno@uol.com.br

Anamaria Silva Neves é doutora em Psicologia pela Universidade de São Paulo, com pós-doutorado na London Metropolitan University, em Londres (20092010). Atualmente é professora Associado 1 no curso de Psicologia da Universidade Federal de Uberlândia. E-mail: anamaria@umuarama.ufu.br 